\title{
DUAL EFFECT OF NEUTROPHILS ON SECRETORY COMPONENT PRODUCTION BY HUMAN BRONCHIAL EPITHELIAL CELLS
}

C. Pilette, B. Detry, A. Guisset and Y. Sibille

Unit of Pneumology and Microbiology, University of Louvain (UCL), Brussels, Belgium

WINNING ABSTRACT: A decreased bronchial expression of secretory component (SC) was demonstrated in severe COPD, and correlated with neutrophils. Mechanisms of epithelial cell/neutrophils interactions remain however poorly understood.

Calu-3 (human bronchial epithelial) cells were incubated after confluence (in triplicate conditions) with various ratios of activated neutrophils (0.5:1 to 15:1, neutrophils: Calu-3 cells). After 48 hrs of co-culture supernatants were assayed for SC by ELISA.

SC production by Calu-3 cells increased at intermediate neutrophil numbers $\left(316 \pm 32\right.$ versus $193 \pm 19 \mathrm{ng} \cdot \mathrm{ml}^{-1}$, ratio of $5: 1$ versus control, mean \pm SEM of 3 experiments, $p=0.05$ ). In contrast, a trend for decrease in SC was observed with high neutrophil numbers $\left(111 \pm 19\right.$ versus $193 \pm 19 \mathrm{ng} \cdot \mathrm{ml}^{-1}$, ratio of $15: 1$ versus control, $\left.\mathrm{p}=0.06\right)$. The addition of secretory leukocyte protease inhibitor further increased SC upregulation at intermediate ratios, and inhibited the SC decrease at high neutrophil numbers. The mechanism of SC up-regulation by neutrophils did not implicate TNF- $\alpha$ or IL-1ß.

This study provides direct evidence of a dual effect of neutrophils on epithelial SC. Our data suggest that neutrophils could differently affect epithelial immune secretory function according to the extent of neutrophil influx and/or to the reactivity of airway epithelial cells.

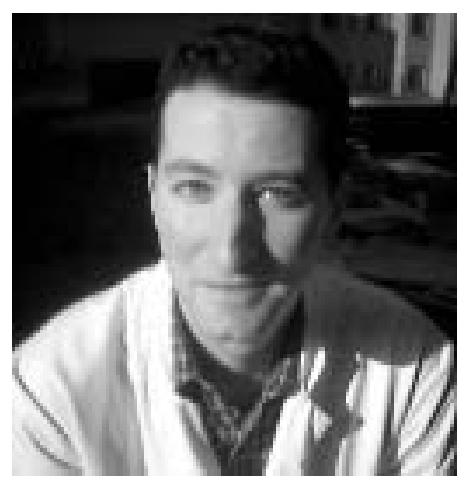

Charles Pilette

Unit and Dept of Pneumology, University of Louvain (UCL), Brussels, Belgium

\section{MY JOB AND THE UNIT IN WHICH I WORK}

I work in the laboratory of mucosal immunity (Unit of Pneumology and Microbiology) of the University of Louvain and in the Department of Pneumology of the Cliniques Universitaires St-Luc, Brussels, Belgium. Our research unit has a long-standing interest in the role of mucosal immunology and immunoglobulin (Ig)A in airway responses, with more recent focus on responses to inhaled antigens and biotoxics relevant to respiratory diseases, such as asthma and chronic obstructive pulmonary disease (COPD). I am involved in two main projects of our unit, as follows: 1) the role of $\operatorname{IgA}$ and epithelial changes in COPD; and 2) the role of IgA antibodies to inhaled antigens in tolerance and allergic asthma. To this end, we are using appropriate research tools (including cultures of epithelial cells and leukocytes, purification of serum immunoglobulins/antibodies, immunoassays and realtime PCR techniques) and pursue an up-and-running close relationship with the Allergy Clinic and the Thoracic
Department (Cliniques UCL St-Luc, Brussels and MontGodinne, Yvoir) for recruitment of volunteers (blood sampling, surgical lung specimens). I work in the Pneumology Department, under the responsibility of Prof. Dr Rodenstein, with a particular interest in airways diseases and allergies, also allowing for patient recruitment. We are currently developing an Asthma Clinic with the aim to improve the management of our less well-controlled patients as well as the assessment of asthma phenotypes and prevalence within our area.

My contribution within our research team is to pilot the two above-mentioned projects, under the supervision of Prof. Yves Sibille, and with the help of two technicians and of a part-time $\mathrm{PhD}$. More recently, in collaboration with Dr F. Huaux and Prof. Lison (Toxicology Unit, UCL Brussels), we have begun murine experiments to investigate the role of $\operatorname{IgA}$ in vivo, in polymeric Ig receptor $(\mathrm{pIgR})^{-/-}$mice in models of COPD and asthma.

\section{MY WINNING ABSTRACT AS PART OF MY RESEARCH}

Our research focuses on the role of IgA and mucosal immunity in airway responses. IgA is the main antibody isotype in mucosal secretions, including in the respiratory tract, and contributes to frontline mechanisms of defence along with mucociliary clearance and innate epithelial-derived factors. IgA is produced by mucosal subepithelial plasma cells in dimeric form (in contrast to serum IgA, which is mainly monomeric), and dimeric Ig $\mathrm{A}$ is actively transported across the airway epithelium by a receptor-mediated transcellular routing assumed by the pIgR. At the apical pole of the airway epithelial cell, the IgA-pIgR complex is cleaved from the cell membrane to release secretory $\operatorname{IgA}$, which is formed by dimeric IgA covalently bound to the extracellular part of the pIgR, called the secretory component (SC). The identified regulatory mechanisms of $\mathrm{pIgR} / \mathrm{SC}$ expression in mucosal tissues implicate mainly cytokines, such as interferon- $\gamma$, 
tumour necrosis factor- $\alpha$ and interleukin- 4 . Putative changes in pIgR expression in mucosal diseases (chronic inflammatory diseases of the bowel or of the airways) have been poorly investigated.

My PhD thesis, entitled "Secretory immunity and polymorphonuclear neutrophils in COPD" and completed in 2002, demonstrated that the expression of the pIgR is strongly decreased in the bronchial epithelium of patients with severe COPD but not in smokers without COPD. Moreover, pIgR expression correlated with lung function tests of airway obstruction, such as the forced expiratory volume in one second, and with neutrophilic infiltration of bronchial glands.

In order to address the mechanisms of the reduced expression of $\mathrm{pIgR/SC}$ in the airways of COPD patients, in vitro experiments on human bronchial epithelial cells (HBEC) are performed in a model of polarised cell culture. Primary HBEC are obtained from lung specimens of patients undergoing surgery for a solitary lung tumour, and cultured on insert-type filters. We have previously shown that, while neutrophil serine-proteinases (elastase and proteinase-3) can cleave pIgR/ $\mathrm{SC}$ into nonfunctional fragments, whole supernatants from activated neutrophils upregulate $\mathrm{pIgR} / \mathrm{SC}$ production by primary cells from non-COPD subjects. This effect of neutrophils is dependent on activation of p38 mitogen-activated protein kinase and nuclear factor- $\kappa \mathrm{B}$ signalling pathways. We aim to determine whether the response to neutrophils of primary cells from COPD patients could be affected, presumably being related to intrinsic changes of COPD airway epithelial cells. The response of primary HBEC from COPD patients will be assessed in a model of co-culture of HBEC and neutrophils that was recently set up in our laboratory (the topic of our presentation to the European Respiratory Society Congress 2006), providing direct evidence of the dual effect of neutrophils on pIgR/SC. Real-time quantitative PCR for $\mathrm{pIgR/SCmRNA} \mathrm{is} \mathrm{also} \mathrm{performed} \mathrm{to} \mathrm{confirm} \mathrm{a} \mathrm{transcriptional}$ activation of the $\mathrm{IIgR}$ gene in HBEC stimulated by neutrophils, and to determine whether the putative impairment of COPD epithelial cell response to neutrophils implicates transcriptional or post-transcriptional mechanisms.

Our COPD patient data suggested that the impairment of bronchial secretory immunity could play a role in COPD pathogenesis, a hypothesis that will be addressed in $\mathrm{pIgR}^{-/-}$ mice studies. These mice have been recently obtained from Prof. P. Brandtzaeg and Dr F-E. Johanson (both Olso, Norway). A long-term (3-month) exposure to low-dose endotoxin will be carried out as a model of COPD airway pathology.

\section{MY RESEARCH AS PART OF MY WORKING GROUP/ RESEARCH TEAM}

We have three main ongoing projects, as follows: 1) the role of epithelial pIgR/secretory IgA deficiency in COPD; 2) the role of $\operatorname{IgA}$ antibodies in tolerance to inhaled allergens in allergic asthma; and 3) regulation of epithelial responses to respiratory syncytial virus (RSV) infection.
The role of $\mathrm{pIgR}$ deficiency, identified in severe COPD patients, is investigated in $\mathrm{pIgR}^{-/-}$mice, to determine whether the decreased expression of $\mathrm{pIgR/SC}$ in COPD airways represents a consequence of the disease or is implicated as a driving factor of its development, playing a causative role and presumably related to intrinsic changes of the COPD bronchial epithelium. The susceptibility of $\mathrm{pIgR}^{-/-}$mice will be investigated in the model of COPD induced by long-term exposure to low-dose endotoxin, as compared with wild-type mice, and will include functional and biomolecular assessments of airflow obstruction (body plethysmography) and airway inflammation (e.g. bronchoalveolar lavage (BAL) cytokines/ chemokines, BAL and tissue neutrophils) following exposure. Mechanistic studies of bronchial epithelial cells from COPD patients, and particularly of their reactivity to neutrophils, is addressing putative changes of the COPD bronchial epithelium function that could underlie defects in the regulation of pIgR expression. The presented poster was within this field of our research. Proteomic and genomic studies of lung and blood specimens, from both COPD patients and smokers without COPD, will show whether polymorphisms or deletions within the $p \operatorname{Ig} R$ gene are associated with low $\mathrm{pIgR}$ expression and with the susceptibility to develop the disease and/or its progression (decline in lung function and severity of airflow limitation).

The role of the specific $\operatorname{Ig} \mathrm{A}$ response to inhaled allergens, identified in allergic patients with rhinitis and asthma to grass pollen, is evaluated through different studies relevant to allergic responses and mucosal tolerance. Allergen-specific IgA antibodies are purified from the serum of allergen-specific immunotherapy-treated patients in order to assess their biological activities on allergic cellular responses, e.g. IgEmediated basophil degranulation, facilitated antigen presentation by B-cells and regulation of dendritic cells. Along with these in vitro experiments, the role of secretory $\operatorname{IgA}$ will be assessed in vivo by studying $\mathrm{pIgR}^{-/-}$mice for their susceptibility to develop allergic responses to inhaled antigens, such as ovalbumin, following the classical (intraperitoneal) sensitisation/(aerosol) provocation protocol.

Our third ongoing project relates to epithelial responses to viral infection and T-cell cytokines. More particularly, the expression of pIgR/SC and Clara cell protein (CC16) is assessed by ELISA and real-time PCR in cultures of human bronchial epithelial cells (NCI-H292 cell line or primary HBEC) exposed to interferon- $\gamma$ and/or RSV. In contrast to $\mathrm{pIgR/SC}$, which is upregulated by interferon- $\gamma$, the production of $\mathrm{CC} 16$ is inhibited. It was demonstrated that CC16 downregulation by interferon- $\gamma$ relates to suppression of Sp1-dependent gene transcription. Interestingly, it was also observed that CC16 concentration is reduced in the serum of children during the early phase of RSV bronchiolitis. Studies are ongoing to further characterise the protective responses of the bronchial epithelium to viral infection and cytokines and their mechanisms, and how these responses could interfere with epithelial cell/virus interactions. 